\title{
Prevalence of Shape-related Developmental Dental Anomalies in India: A Retrospective Study
}

\author{
Mridula Goswami ${ }^{1}$, Sakshi Bhardwaj ${ }^{2}$, Navneet Grewal ${ }^{3}$
}

\begin{abstract}
Aim and objective: The aim and objective of this study was to review the literature to analyze the prevalence of developmental dental anomalies regarding shape in India.

Background: Although there have been several studies investigating the prevalence of individual dental anomalies related to shape, only a few studies considered all subtypes and their distribution among genders, especially in India.

Results: An electronic search was made in the PUBMED database to review prevalence-based data on developmental dental anomalies related to shape in India up to December 2018. A diverse range of results regarding prevalence of developmental dental anomalies related to shape were seen in these studies due to vast regional, cultural, and ethnic diversities and various environmental factors affecting the tooth development.

Conclusion: There is a necessity to conduct more study on shape-related dental anomalies because there are very limited studies regarding prevalence of concrescence, dilacerations, and accessory root and various associated factors.

Clinical significance: Early diagnosis and timely management of these anomalies can prevent complications. The knowledge on identification and prevalence of dental anomalies helps the dental practitioners improve the treatment plan. The prevalence studies can be of utmost importance in the formulation of oral healthcare programs by using their data to analyze the intensity of dental anomalies.
\end{abstract}

Keywords: Developmental dental anomalies, Prevalence, Shape.

International Journal of Clinical Pediatric Dentistry (2020): 10.5005/jp-journals-10005-1785

\section{INTRODUCTION}

Developmental dental anomalies related to shape are an integral part of dental morphological variations. They are caused due to disturbances occurring during the morpho-differentiation stage of tooth development. ${ }^{1}$ The prevalence of dental anomalies can help in getting information regarding the genetic and phylogenetic aspects, as more than 300 genes take part in the intricate process of tooth formation. Sometimes, these can be the result of chromosomal abnormalities that may be X-linked also, and therefore their prevalence can be higher in one gender when compared to the other. The morphology of tooth relies on various gene expression in ectomesenchyme. It is dependent on fibroblast growth factor-8 (FGF-8) in the early molar domains and bone morphogenetic protein- 4 in the anterior regions. The signaling factors such as bone morphogenetic protein (BMP), fibroblast growth factor (FGF), tumor necrosis factor(TNF), WNT signaling pathway, and Sonic hedgehog $(\mathrm{SHH})$ plays an essential role in the complicated bending in the enamel organ during morphogenesis. ${ }^{2}$ The genes involved in root anomalies are SHH), WNT signaling pathway, BMP, Transforming growth factor beta(TGF-B), and Nuclear Factor I-C(NFIC) because they are involved in signaling pathway between hertwigs epithelial root sheath and mesenchyme. ${ }^{3}$ These variations can be of two types, primary or secondary. The primary variations are inherited which are caused due to genes or chromosomal aberrations. The secondary variations may be due to environmental factors, such as changes in genetic composition, prenatal and postnatal events like any change occurring during the mineralization, or maturation process of the tooth that will affect the mineralized component like enamel, dentin, or the cementum. ${ }^{4}$ The anomalies affecting the morphology of teeth comprise of talon cusp, dens invaginatus, dens evaginatus, gemination, fusion, root

\footnotetext{
1,2 Department of Pedodontics and Preventive Dentistry, Maulana Azad Institute of Dental Sciences, New Delhi, India

${ }^{3}$ Department of Pedodontics and Preventive Dentistry, Government Dental College, Amritsar, Punjab, India

Corresponding Author: Sakshi Bhardwaj, Department of Pedodontics and Preventive Dentistry, Maulana Azad Institute of Dental Sciences, New Delhi, India, Phone: +91 9454561952, e-mail: sakshi.bhrdwj@ gmail.com

How to cite this article: Goswami M, Bhardwaj S, Grewal N. Prevalence of Shape-related Developmental Dental Anomalies in India: A Retrospective Study. Int J Clin Pediatr Dent 2020;13(4):407-411.

Source of support: Nil

Conflict of interest: None
}

dilacerations, taurodontism, concrescence, and supernumerary roots. The most commonly seen anomaly related to shape is fused teeth. $^{5}$

Developmental dental anomalies of permanent dentitition, in comparison to their primary counterpart, can lead to both shortand long-term complications subsequently causing irreversible damages. The anomaly may involve only a single tooth or may be a component of a syndrome. These anomalies generally remain unnoticed in clinical practice, as they are rarely the chief complaint of the patient and is overcome by other common oral diseases such as dental caries or periodontal diseases. ${ }^{6}$ The anomalous teeth are often asymptomatic and may be discovered during clinical and radiographic examination of the oral cavity. Complications associated with anomalous primary teeth result in an unsightly appearance of the affected teeth, malocclusion, increased susceptibility to caries, troublesome eruption of succedaneous 
Table 1: Review of studies of shape anomalies_fusion and gemination

\begin{tabular}{|c|c|c|c|c|c|c|}
\hline Study & Year & Subjects (n) & $\begin{array}{l}\text { Age of the } \\
\text { subjects }\end{array}$ & $\begin{array}{l}\text { Gender } \\
\text { proportion (M:F) }\end{array}$ & Results-prevalence & $\begin{array}{l}\text { Results-gender } \\
\text { proportion (M:F) }\end{array}$ \\
\hline 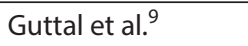 & 2010 & 20,182 & $>14$ years & - & Gemination + Fusion: $0.084 \%$ & - \\
\hline Kathariya et al..$^{5}$ & 2013 & 600 & Not mentioned & $1.06: 1$ & Gemination + Fusion: $3 \%$ & $1.57: 1$ \\
\hline Shashirekha, Jena ${ }^{6}$ & 2013 & 1,062 & $15-30$ years & 2.14 & Gemination + Fusion: $0.46 \%$ & - \\
\hline $\begin{array}{l}\text { Mukhopadhyay, } \\
\text { Mitra }^{15}\end{array}$ & 2014 & 2,757 & $4-6$ years & 1.14 & Gemination + Fusion: $0.39 \%$ & - \\
\hline Lochib et al. $^{16}$ & 2015 & 1,000 & $3-5$ years & $1.14: 1$ & Gemination + Fusion: $0.5 \%$ & - \\
\hline Shilpa et al. ${ }^{7}$ & 2017 & 4,180 & $2-6$ years & $1.6: 1$ & Gemination + Fusion: $0.95 \%$ & $1.66: 1$ \\
\hline
\end{tabular}

- Not specified

teeth, and difficulties during endodontic or surgical procedure of the affected tooth. The well-timed intervention would minimize complications in the permanent dentition. ${ }^{6}$ Their identification in the initial stage is important because they are helpful in precise and timely diagnosis of complex genetic abnormalities which include the craniofacial region and in the treatment for better smiles in the future.

In developing countries such as India, the number of patients attending the dental outpatient department can be misleading in the calculation of prevalence. The prevalence would bring the attention of various dental faculties to the prevailing dental anomalies which would help in early identification as well as in comprehensive treatment of such conditions. ${ }^{7}$ The aim of this study was to review the literature to analyze the prevalence of developmental dental anomalies regarding shape in India.

\section{Materials and Methods}

An electronic search was made in the PUBMED database to review prevalence-based data in India up to December 2018 using the key search terms "developmental dental anomalies", "shape anomalies," "gemination," "fusion," "concrescence," "dilaceration," "talons cusp," "dens invaginatus," "dens evaginatus," "taurodontism," "supernumerary roots". The articles were selected after reviewing the titles and abstracts to ascertain eligibility. Articles were selected initially for review, and others were added proceeding from a manual search and from any references in the review articles that were thought to be relevant. All original studies published on PUBMED involving prevalence-based data of developmental dental anomalies of shape in India up to December 2018 were considered eligible for the present study.

\section{Discussion}

Although there have been several studies investigating the prevalence of individual dental anomalies related to shape, only a few studies considered all subtypes and their distribution among genders, especially in India. Anomalies of shape include fusion and gemination, talons cusp, dens invaginatus, dens evaginatus, root dilacerations, taurodontism, and concrescence.

\section{Fusion and Gemination}

Fusion and gemination is defined as double teeth that seems to be greater than standard size of tooth. Gemination can be referred as an enlarged tooth or united tooth with the tooth count considered normal when the anomalous tooth is counted as one. Fusion is an augmented tooth with the teeth count lesser than normal when the anomalous tooth is counted as one. ${ }^{8}$ The complications caused by double teeth are compromised esthetics, crowding of teeth, and reduced space for eruption of adjoining teeth. ${ }^{9,10}$

The prevalence of fusion and gemination combined was found to be 0.084 to $3 \%$ in our study, with highest prevalence reported in Maharashtra and lowest in West Bengal. The reason for such varying range was mainly attributed to study design, inclusion and exclusion criteria, and the sampling technique used. The frequency was higher in males when compared to females.

The prevalence of fusion and gemination reported in our study was comparable to other international studies. The prevalence of fusion and gemination was found to be $0.8 \%$ in Saudi Arabian population, ${ }^{11} 2.5 \%$ in Solvenia, ${ }^{12} 0.09 \%$ in southeast Iranian population, ${ }^{13}$ and $1.6 \%$ in Mexico. ${ }^{14}$ The frequency was higher in male than in female which is similar to our study (Table 1).

\section{Concrescence}

The fusion of two adjoining teeth by their cementum is known as concrescence. It poses a problem in treating the tooth surgically or endodontically due to anomalous structure and makes it difficult to carry out various orthodontic and periodontal procedures.

There were only two studies calculating the prevalence of concrescence in India in PUBMED. The prevalence was found to be $0.019 \%$ in one study with female predilection. The prevalence was found to be $0.09 \%$ in other study with male predilection. The difference in results can be attributed to different gender proportion in the population of different region, and the data pertaining to the prevalence of concrescence is very limited in India and worldwide. The prevalence is higher in international studies where the prevalence was $0.36 \%$ in French population. ${ }^{17}$

\section{Dilaceration}

The presence of an atypical bend in the root or crown of a tooth is known as dilaceration. It is commonly present in the root; however, presentation on any part of the tooth is possible. The complications caused make it difficult to carry out surgical and endodontic procedures.

There were only two studies determining the prevalence of dilaceration in India. The prevalence of dilaceration was found to be 0.39 in one study with male predilection. ${ }^{9}$ The prevalence was found to be $16.48 \%$ in the other study with female prediliction. ${ }^{4}$ The variations in result is mainly due to sampling technique, ethnic diversity, and different inclusion criteria. The prevalence in international studies was found to be $5.29 \%$ in southeastern Iranian population ${ }^{11}$ and $0.18 \%$ in French population. ${ }^{17}$ There have been very limited studies conducted on the prevalence of dilacerations. 


\begin{tabular}{|c|c|c|c|c|c|c|}
\hline Study & Year & Subjects (n) & $\begin{array}{l}\text { Age of the } \\
\text { subjects }\end{array}$ & $\begin{array}{l}\text { Gender proportion } \\
\text { (M:F) }\end{array}$ & $\begin{array}{l}\text { Results-prevalence } \\
(\%)\end{array}$ & $\begin{array}{l}\text { Results-gender } \\
\text { proportion (M:F) }\end{array}$ \\
\hline \multicolumn{7}{|l|}{ Concrescence } \\
\hline Guttal et al. ${ }^{9}$ & 2010 & 20,182 & $>14$ years & - & 0.019 & $1: 3$ \\
\hline Goutham et al. ${ }^{4}$ & 2017 & 1,080 & 18-62 years & $1: 1$ & 0.09 & $1: 0$ \\
\hline \multicolumn{7}{|l|}{ Dilaceration } \\
\hline Guttal et al. ${ }^{9}$ & 2010 & 20,182 & $>14$ years & - & 0.39 & $1.28: 1$ \\
\hline Goutham et al. ${ }^{4}$ & 2017 & 1,080 & $18-62$ years & $1: 1$ & 16.48 & $0.91: 1$ \\
\hline \multicolumn{7}{|c|}{ Supernumerary roots } \\
\hline Garg et al. ${ }^{19}$ & 2010 & 586 & $15-75$ & $0.83: 1$ & 5.9 & $0.59: 1$ \\
\hline Guttal et al. ${ }^{9}$ & 2010 & 20,182 & $>14$ years & - & 0.034 & $1.33: 1$ \\
\hline
\end{tabular}

- Not specified

Table 3: Review of studies of shape anomalies—talons cusp

\begin{tabular}{lllllll}
\hline Study & Year & Subjects $(n)$ & $\begin{array}{l}\text { Age of the } \\
\text { subjects }\end{array}$ & $\begin{array}{l}\text { Gender proportion } \\
\text { (M:F) }\end{array}$ & $\begin{array}{l}\text { Results- prevalence } \\
\text { (\%) }\end{array}$ & $\begin{array}{l}\text { Results-gender } \\
\text { propotion (M:F) }\end{array}$ \\
\hline${\text { Guttal et al. }{ }^{9}}^{21}$ & 2010 & 20,182 & $>14$ years & - & 0.07 & $1: 2$ \\
Prabhu et al. $^{12}$ & 2012 & 2,740 & 4-60 years & $1.25: 1$ & 0.58 & $3: 1$ \\
Gupta et al. $^{1}$ & 2014 & 1,123 & $>14$ years & $1.04: 1$ & 0.97 & $1.75: 1$ \\
Mukhopadhyay, Mitra $^{15}$ & 2014 & 2,757 & 4-6 years & $1.14: 1$ & 0.07 & $1: 1$ \\
Shilpa et al. & 2017 & 4,180 & 2-6 years & $1.6: 1$ & 0.47 & - \\
\hline
\end{tabular}

- Not specified

\section{Supernumerary Roots}

The presence of extra roots in the tooth is known as supernumerary roots. It is commonly present in mandibular region with teeth mostly affected being canines, premolars, and molars, chiefly third molars.

There have been limited studies on the prevalence of supernumerary roots; therefore, there are not much data available regarding gender predilection. The prevalence in one study was $0.034 \%$ with higher frequency in males. ${ }^{9}$ The prevalence was found to be $5.9 \%$ in the other study with higher frequency in females. ${ }^{12}$ The variations were due to different regions and ethnic groups. The prevalence in international studies was found to be $2 \%$ in the Iranian population ${ }^{13}$ and $1.35 \%$ in German population (Table 2). ${ }^{18}$

\section{Talons Cusp}

The presence of irregular expansion of pulp within normal enamel and dentin is known as Talons cusp. The appearance of the crown contour may be of T-type if it extends to the incisal edge or Y-type if it extends more cervically. ${ }^{20}$ It is also called as interstitial cusp, tuberculated premolar, evaginated odontoma, occlusal enamel pearl, occlusal anomalous tubercle, or supernumerary cusp. It is most commonly seen in maxillary arch with the tooth most commonly involved being lateral incisor. The problems posed due to the presence of talons cusp affect esthetics adversely, interference during occlusion, and complications during endondontic, surgical, and periodontal treatment. ${ }^{9}$

Its prevalence ranged between 0.07 and $0.97 \%$ in the present study with no gender predilection, as it was having higher, lower, or similar frequency in males when compared to females in different study. The difference is due to difference in composition of the population under study depending on gender and region.
The prevalence of talons cusp was found to be lower than other international studies. The prevalence of talons cusp was $1.4 \%$ in Saudi Arabian population ${ }^{11}$ and $3.4 \%$ in Solvenia; ${ }^{12}$ also, the anomaly was female predominant which is partially similar to our study (Table 3).

\section{Dens Invaginatus}

The presence of introversion mainly on the crown and occasionally on the root of the tooth bounded by enamel and dentin results in an anomaly known as Dens invaginatus. It is most commonly seen on the anterior tooth as a pit or fissure on the lingual surfaces. It radiographically has a peculiar presentation of a pear-shaped invagination narrowing on the surface of the teeth. Tooth with dens invaginatus are highly susceptible to pulpal exposure without much clinical involvement due to tortuous lingual anatomy as there is thin enamel present. ${ }^{9}$

The prevalence in the present study was found to be 0.019 to $0.40 \%$, with higher frequency in males compared to females. The difference in prevalence was mainly due to difference in sampling technique. The prevalence in other international studies was similar to the French population with around $0.18 \%{ }^{17}$ or it was higher as in southeast Iranian population with $1.37 \% .{ }^{11}$ Also in these studies, the prevalence in male was higher compared to female which is similar to our study. ${ }^{22}$

\section{Dens Evaginatus}

The appearance of an extra cusp on the surface of the tooth caused due to protuberance (horn-like) extruding outward on localized region on the crown is known as Dens evaginatus. The most common site of occurrence is occlusal surface in premolars and molars and cingulum area in canines and incisors. It may lead to 
Prevalence of Shape-related Developmental Dental Anomalies

Table 4: Review of studies of shape anomalies_dens invaginatus and dens evaginatus

\begin{tabular}{|c|c|c|c|c|c|c|}
\hline Study & Year & Subjects (n) & $\begin{array}{l}\text { Age of the } \\
\text { subjects }\end{array}$ & $\begin{array}{l}\text { Gender proportion } \\
\text { (M:F) }\end{array}$ & $\begin{array}{l}\text { Results-prevalence } \\
\text { (\%) }\end{array}$ & $\begin{array}{l}\text { Results-gender } \\
\text { proportion }(M: F)\end{array}$ \\
\hline \multicolumn{7}{|l|}{ Dens invaginatus } \\
\hline Guttal et al. ${ }^{9}$ & 2010 & 20,182 & $>14$ years & - & 0.019 & $9: 1$ \\
\hline Patil et al. ${ }^{25}$ & 2013 & 4,133 & $13-38$ years & $0.96: 1$ & 0.4 & $1.37: 1$ \\
\hline Shashirekha, Jena ${ }^{6}$ & 2013 & 1,062 & $15-30$ years & 2.14 & 0.18 & \\
\hline \multicolumn{7}{|l|}{ Dens evaginatus } \\
\hline Guttalet al. ${ }^{9}$ & 2010 & 20,182 & $>14$ years & - & 0.04 & $9: 1$ \\
\hline Gupta et al. ${ }^{1}$ & 2014 & 1,123 & $>14$ years & 1.04 & 2.40 & $0.66: 1$ \\
\hline
\end{tabular}

- Not specified

Table 5: Review of studies of shape anomalies_taurodontism

\begin{tabular}{lllllll}
\hline Study & Year & Subjects $(n)$ & $\begin{array}{l}\text { Age of the } \\
\text { subjects }\end{array}$ & $\begin{array}{l}\text { Gender proportion } \\
\text { (M:F) }\end{array}$ & $\begin{array}{l}\text { Results-prevalence } \\
\text { (\%) }\end{array}$ & $\begin{array}{l}\text { Results-gender } \\
\text { proportion (M:F) }\end{array}$ \\
\hline Guttal et al. $^{9}$ & 2010 & 20,182 & $>14$ years & - & 0.3 & $1.17: 1$ \\
Gupta et al. $^{1}$ & 2011 & 1,123 & $>14$ years & 1.04 & 2.49 & $0.72: 1$ \\
Patil et al. $^{25}$ & 2013 & 4,133 & $13-38$ years & $1.07: 1$ & 0.4 & $1.12: 1$ \\
Bharti et al. $^{27}$ & 2015 & 1,000 & 20-70 years & $1: 1$ & 2.8 & $1.54: 1$ \\
\hline
\end{tabular}

- Not specified

interference during occlusion followed by deviation in the position of the tooth. ${ }^{9}$

In the present study, the prevalence of dens evaginatus was found to be $0.04-2.40 \%$. There was no gender predilection, as in one study, it was female predominant and in the other it was male predominant which was due to difference in sampling technique and regional changes. The prevalence in international study was in the range of our study with $1.01 \%$ in the Thai population. ${ }^{23}$ The prevalence was higher in females and was found to be $3 \%$ in Hong Kong Chinese patients ${ }^{24}$ and the prevalence was more in female when compared to males but there was no prevalence in French population which shows higher predilection of this anomaly in the Asian population (Table 4).

\section{Taurodontism}

The presence of enlarged crown with diminished roots and furcation near apex of the tooth is known as taurodontism. The anomaly is clinically seen in molar teeth. The common presentation is huge pulp chambers with displacement of the furcation area apically with subsequent increase in apico-occlusal height and reduced convergence at CEJ. The tooth with taurodontism poses a hindrance in the endodontic treatment. ${ }^{9}$

The prevalence in the present study was $0.3-2.8 \%$ which was generally seen in males when compared to females. ${ }^{26}$ It was seen higher in international studies like in French population with a prevalence of around $15 \%{ }^{17}$ and in Southeast Iranian population with frequency of $5.58 \%$ with higher prevalence in females compared to males ${ }^{13}$ (Table 5).

\section{Conclusion}

There are is very limited PUBMED-based data available on dental anomalies related to shape in India. There are only a few studies conducted in the past which find the association of dental anomalies with the other factors. Also, a diverse range of results were seen in these studies due to a vast regional, cultural, ethnic diversity, and various environmental factors affecting the tooth development. The limited data on dental anomalies such as concrescence, dilacerations, and accessory roots should encourage the professionals to understand the importance of identifying and reporting them so that the data pertaining to these anomalies can be more useful not only in India but worldwide.

Early diagnosis and timely management of these anomalies can prevent complications, and knowledge on identification and prevalence of dental anomalies helps the dental practitioners improve the treatment plan. The prevalence studies can be of utmost importance in the formulation of oral healthcare programs by using their data to analyze the intensity of dental anomalies.

\section{References}

1. Gupta SK, Saxena P, Jain S, et al. Prevalence and distribution of selected developmental dental anomalies in an Indian population. J Oral Sci 2011;53(2):231-238. DOI: 10.2334/josnusd.53.231.

2. Cobourne MT, Sharpe PT. Diseases of the tooth: the genetic and molecular basis of inherited anomalies affecting the dentition. Wiley Interdiscip Rev Dev Biol 2013;2(2):183-212. DOI: 10.1002/wdev.66.

3. Fons Romero JM, Star H, Lav R, et al. The impact of the Eda pathway on tooth root development. J Dent Res 2017;96(11):1290-1297. DOI: 10.1177/0022034517725692.

4. Goutham B, Bhuyan L, Chinnannavar SN, et al. Prevalence of dental anomalies in Odisha population: a panoramic radiographic study. J Contemp Dent Pract 2017;18(7):549-553. DOI: 10.5005/ jp-journals-10024-2082.

5. Kathariya MD, Nikam AP, Chopra K, et al. Prevalence of dental anomalies among school going children in India. J Int Oral Health 2013;5(5):10-14.

6. Shashirekha G, Jena A. Prevalence and incidence of gemination and fusion in maxillary lateral incisors in odisha population and related 
case report. J Clin Diagnos Res 2013;7(10):2326-2329. DOI: 10.7860/ JCDR/2013/5677.3516.

7. Shilpa G, Gokhale N, Mallineni SK, et al. Prevalence of dental anomalies in deciduous dentition and its association with succedaneous dentition: a cross-sectional study of 4180 South Indian children. J Indian Soc Pedod Prev Dent 2017;35:56-62. DOI: 10.4103/09704388.199228

8. Vasudev SK, Goel BR. Endodontic management of dens evaginatus of maxillary central incisors: a rare case report. J Endod 2005;31(1):67-70. DOI: 10.1097/01.don.0000137645.87493.cd.

9. Guttal KS, Naikmasur VG, Bhargava P, et al. Frequency of developmental dental anomalies in the Indian population. Eur J Dent. 2010;4:263-269.

10. Oliván-rosas G, López-jiménez J, Giménez-prats MJ, et al. Considerations and differences in the treatment of a fused tooth. Med Oral 2004;9:224-228.

11. Yassin SM. Prevalence and distribution of selected dental anomalies among Saudi children in Abha, Saudi Arabia. J Clin Exp Dent 2016;8(5):e485-e490. DOI: 10.4317/jced.52870.

12. Fekonja A. Prevalence of dental developmental anomalies of permanent teeth in children and their influence on esthetics. J Esthet Restor Dent 2017;29(4):276-283. DOI: 10.1111/jerd.12302.

13. Saberi EA, Ebrahimipour S. Evaluation of developmental dental anomalies in digital panoramic radiographs in Southeast Iranian population. J Int Soc Prev Commun Dent 2016;6(4):291-295. DOI: 10.4103/2231-0762.186804.

14. Sedano HO, Carreon Freyre I, Garza de la Garza ML, et al. Clinical orodental abnormalities in mexican children. Oral Surg Oral Med Oral Pathol 1989;68:300-311. DOI: 10.1016/0030-4220(89) 90215-6.

15. Mukhopadhyay S, Mitra S. Anomalies in primary dentition: their distribution and correlation with permanent dentition. J Nat Sci Biol Med 2014;5(1):139-143. DOI: 10.4103/0976-9668. 127313.

16. Lochib S, Indushekar KR, Saraf BG, et al. Occlusal characteristics and prevalence of associated dental anomalies in the primary dentition. J Epidemiol Glob Health 2015;5:151-157. DOI: 10.1016/ j.jegh.2014.07.001.

17. Baron C, Houchmand-Cuny M, Enkel B, et al. Prevalence of dental anomalies in French orthodontic patients: a retrospective study. Arch Pediatr 2018;25(7):426-430. DOI: 10.1016/j.arcped.2018.07.002.

18. Schäfer $E$, Breuer $D$, Janzen $S$. The prevalence of three-rooted mandibular permanent first molars in a German population. J Endod 2009;35:202-205. DOI: 10.1016/j.joen.2008.11.010.

19. Garg AK, Tewari RK, Kumar A, et al. Prevalence of three-rooted mandibular permanent first molars among the Indian population. J Endod 2010;36(8):1302-1306. DOI: 10.1016/j.joen.2010.04.019.

20. Segura JJ, Jiménez-Rubio A. Talon cusp affecting permanent maxillary lateral incisors in 2 family members. Oral Surg Oral Med Oral Pathol Oral Radiol Endod 1999;88(1):90-92. DOI: 10.1016/s10792104(99)70199-x.

21. Prabhu RV, Rao PK, Veena K, et al. Prevalence of Talon cusp in Indian population. J Clin Exp Dent 2012;4(1):e23-e27. DOI: 10.4317/ jced.50650.

22. Bäckman B, Wahlin YB. Variations in number and morphology of permanent teeth in 7-year-old Swedish children. Int J Paediatr Dent 2001;11:11-17. DOI: 10.1046/j.1365-263x.2001.00205.x.

23. Reichart $P$, Tantiniran D. Dens evaginatus in the Thai. An evaluation of fifty-one cases. Oral Surg Oral Med Oral Pathol 1975;39(4):615-621. DOI: 10.1016/0030-4220(75)90203-0.

24. Bedi R, Pitts NB. Dens evaginatus in the Hong Kong Chinese population. Endod Dent Traumatol 1988;4:104-107. DOI: 10.1111/ j.1600-9657.1988.tb00305.x.

25. Patil S, Doni B, Kaswan S, et al. Prevalence of dental anomalies in Indian population. J Clin Exp Dent 2013;5(4):e183-e186. DOI: 10.4317/ jced.51119.

26. Aren G, Guven Y, Guney Tolgay C, et al. The prevalence of dental anomalies in a Turkish population. J Istanb Univ Fac Dent 2015;49(3):23-28. DOI: 10.17096/jiufd.86392.

27. Bharti R, Chandra A, Tikku AP, et al. Prevalence of taurodont molars in a North Indian population. Indian J Dent 2015;6(1):27-31. DOI: 10.4103/0975-962X.151700. 